\title{
How to Increase the Athletes Psychological Skills?: Design and Development of Self-talk Guidance for Athletes
}

\author{
Adiska Rani Ditya Candra ${ }^{1}$, Eni Rindi Antika ${ }^{2}$, Kumbul Slamet Budiyanto $^{3}$, Sobihin ${ }^{4}$, \\ Hermawan $^{5}$ \\ \{adiska_rani@mail.unnes.ac.id ${ }^{1}$, rindi@mail.unnes.ac.id ${ }^{2}$, kumbulkang- \\ dipati@mail.unnes.ac.id $\left.{ }^{3}\right\}$ \\ Universitas Negeri Semarang, Semarang, Indonesia ${ }^{1,2,3,4,5}$
}

\begin{abstract}
The study aims to develop and perform validation stages toward the "Self-Talk Guidance" book for athletes. This guide book focused on the steps that must be taken to apply the psychological intervention techniques to self-talk in various situations during training or competition. The target of developing this book is professional athletes who will later be used as research subject. The study uses the ADDIE (Analysis, Design, Development, Implementation, Evaluation) Research and Development model. This research involves experts in fulfilling expert judgment to validate the book developed and to create products that can be used for the testing process directly to check the effectiveness of the product. The results of research analysis obtained by the product have excelent criteria on the results of expert judgment. The conclusion of this research is that the product is feasible to use and ready for product trials and product effectiveness tests.
\end{abstract}

Keywords: Athlete, Psychological Intervention Techniques, Self-talk Guidance.

\section{Introduction}

Increased interest in psychology in the field of sports is seen in various types of research that links the psychological relationship in the world of sports. Several researchers Birrer \& Morgan; Sindik et al; MacNamara et al examines the interrelationship of psychological skills, as well as the identification of talents on the athlete's performance which provides a strong empirical basis on the importance of psychological characteristics in facilitating athlete development in sports [1,2,3]. A developed mindset that provides a solid foundation for intervention and psychological factors is central to many highly beneficial talent development environments [4]. Other studies 
have shown that embedding psychological skills into a development environment ensures that prospective elite athletes use and develop appropriate skills to overcome current and future challenges in their main performance [3].

Psychological skills have an impact on the physical performance of athletes in achieving peak performance. Weinberg and Gould also stated that most coaches think that winning in a match depends on 50\% psychological preparation [5]. Therefore, most athletes do mental training as an additional effort to supplement physical training. Thelwell mentions that mental exercise interventions are used to facilitate specific positive outcomes [6]. Thewel's research results compared several psychological interventions used such as imagery, self-talk, relaxation on athlete performance. It was found that psychological skills can affect performance in different ways.

Psychological skills can be trained and developed through Psychological Skills Training (PST). The importance of psychological skills training (PST) has been recognized and athletes using psychological intervention strategies have also increased [1]. Although interest has increased, several things need attention. First, researchers have recently given reasons for the choice of skills in interventions. Second, many focus on measuring interventions on performance outcomes and the third on the extent to which psychological skills affect performance in the overall competition [6]. Concerning the measurement of psychological interventions, various studies conducted by M. Behnke et al; sindik et al,; zourbanos et al which includes measurements, inventory development and psychological questionnaires $[7,2,8]$.

Some mental training that has been validated include imagery techniques [9], self-talk techniques [10], and pre-work routines [11]. And in this discussion, it refers to the self-talk technique. The sports psychology literature states that self-talk techniques have progressively increased. The study of self-talk by sharing research designs and tasks fully supports that self-talk can be an effective cognitive intervention strategy for performance improvement [12] [13]. The meta-analytic study of self-talk also concludes that the effect of self-talk is recommended and suggested as a strategy to facilitate performance improvement exercises and to be a recommendation for new research directions [14].

However, as many studies have revealed the effect of self-talk on performance, there is no list of materials used as an intervention strategy and its structure has not been established [7]. This refers to the scarcity of research on the structure of the use of strategies for self-talk interventions both procedures and steps to use self-talk. A lack of understanding of the situation that has to do with how the results of applying self-talk to achieve success are impossible [15]. Paying attention to the evidence relating to the effectiveness of self-talk and research that focuses on measuring the level of intervention strategies for improving performance and enhancing psychological skills must be accompanied by how the stages are carried out.

Some recommendations referred to the use of self-talk in enhancing psychological skills require specific guidance for athletes which contains steps for the use of self-talk intervention strategies in practice and competition. This purpose of this research will prepare the design and development that will be used as a basis for further research on the development of the Self-talk Guidance book that can be used by the athletes. 


\section{Methods}

This research is $\mathrm{RnD}$ research using ADDIE model. The purpose of this research is intended to produce designs and develop products that are ready to be tested. The product developed is a guide book on Self-talk Intervention Strategies that can be practiced by athletes and namely "Self-talk Guidance".

Development procedures using the ADDIE model are often used to describe systematic approaches to instructional models and center on individual learning and performance. The ADDIE model by M Branch [16] and clarified by Molenda (2003) in Shelton [17] consists of five phases namely Analyze, Design, Develop, Implement and Evaluate.

1. Analyze contains an analysis of problem identification and product needs analysis

2. The design contains the formulation of the method, the content of the material and the determination of strategies in making the Self-talk guidebook product based on the problem being examined

3. Develop, the stage of product creation and development that results in a self-talk guidance book.

4. Implement, prepare athletes and coaches with research areas that have been conditioned for the implementation of the use of products

5. Evaluated, to evaluate the system development method used and see the results of research.

Table 1. Ratting range for Expert Judgement

\begin{tabular}{lcl}
\hline Scale & Value Range & Criteria \\
\hline 5 & $X>4,21$ & Excelent \\
4 & $3,40<X \leq 4,21$ & Very good \\
3 & $2,60<X \leq 3,40$ & Good \\
2 & $1,79<X \leq 2,60$ & Fair \\
1 & $X \leq 1,79$ & Poor \\
\hline
\end{tabular}

Data analysis techniques to determine product validity using descriptive percentages with the following formula:

$$
P=\frac{\sum x_{i} \times 100 \%}{\sum x_{j}}
$$

Calculation of the percentage results will provide the conclusions presented in the percentage classification as follows:

Table 2. Percentage Classification of Product Feasibility Test

\begin{tabular}{ccc}
\hline Procentage & Clasifie & Justify \\
\hline $75-100 \%$ & Very good & Very feasible to use \\
$50-75 \%$ & Good & Proper to use \\
$25-50 \%$ & Fair & Revised \\
$0-25 \%$ & Poor & Not feasible to use \\
\hline
\end{tabular}




\section{Results and discussions}

\subsection{Results}

A Guidebook on the use of a self-talk intervention strategy called "Self-talk Guidance" has been developed with ADDIE development research procedures. The stages that have been carried out so far include Analysis, Design, and Develop. The results of this research can be described as follows:

a) Analysis

The analysis phase is obtained based on needs analysis and identification of problems that exist in athletes. Furthermore, this analysis phase also looks for gaps or differences between psychological skills training and athlete performance in training and competition. Information was obtained based on the results of interviews with the Coaches, this time represented by the Central Java softball trainer and the chairman of the KONI in Central Java. The results of the analysis and problems identification formulate the main problems such as (1) the coaches states that athletes in a state of urgency often feel unsteady and experience some problems with psychological factors such as anxiety, discomfort, decreased concentration which will have an impact on the results of the throw or punch during competition, (2) the coaches feels there is a need for various exercises combined with psychological skills training, (3) during the training session the athlete also does not understand how to improve psychological skills through psychological intervention strategies.

Based on the results of the analysis obtained that athletes need to get mental training ibased on athlete needs. There is no structured mental training program that makes researchers have a plan and think of strategies so that athletes can have psychological skills with exercises that can be done individually both with coaches and without coaches. The researcher formulated a strategy to create an intervention strategy guide book, Self-talk that would assist athletes in controlling themselves in improving performance related to psychological skills.

\section{b) Design}

The formulation of ideas regarding the development of a self-talk guidance for athletes will be designed at this stage. The design of the content of the material from the book involves colleagues who are engaged in guidance and counseling. This is designed so that the contents of the material do not come out of the context of selftalk guides that are designed for athletes. The design of the book is packed with attention to the breadth of the scope of the material with a calculated theme.

The design of the contents of the book consists of several parts or divided into chapters to make it easier for athletes to understand the contents of the manual. At this stage the researcher also looks for sources both from books or journal articles to complete the material contents Not only preparing materials for the design phase also formulates a questionnaire that will be used for assessment of the feasibility of the book by the expert, and a questionnaire that will be given to the coaches and also the athletes

\section{c) Develop}

At this stage, the design formulation will be developed. scope of the content of several chapters will be made in full and ready to be made into a book as a whole. 
After that, the book validation proses to check whether the book that has been made is feasible for use or not and whether there are revisions that must be made. Validation in expert judgment will be conducted by 2 experts, one of them is a sport psychologist and the other one is guidance and counseling expert.

The initial draft of the development of the Self-talk Guidance book is divided into sections or chapters including:

Chapter 1 Contains instructions for understanding and reading the guidebook.
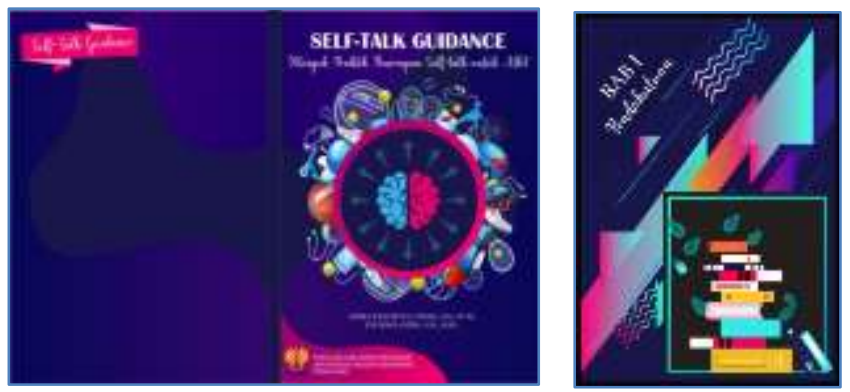

Fig. 1. Cover book of self-talk guidance

Chapter 2 Contains definitions and general descriptions of sports psychology, as well as psychology techniques in sports
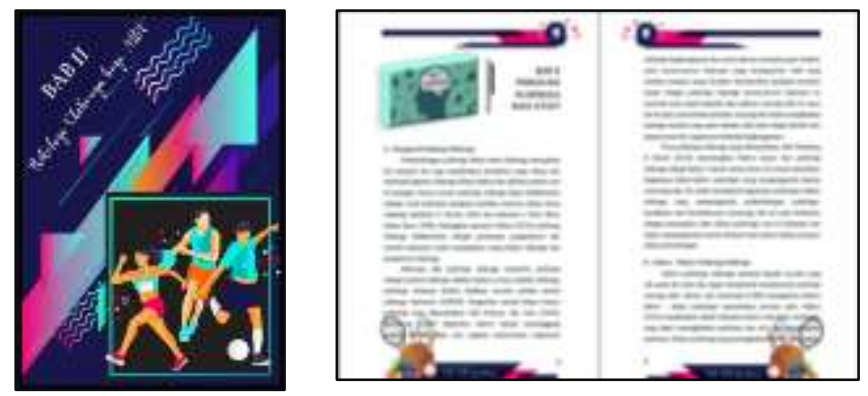

Fig. 2. Content of chapter 2

Chapter 3 Contains a description of the definition of self-talk and the types of selftalk. In the sport psychology self-talk is divided into motivational self-talk and instructional self-talk. In this case a lot of research related to the comparison of these two types of self-talk. In the Self-talk Guidance book, Self-talk is divided into 4 types proposed by Jones $(2003$; 2005) namely (1) Goal Setting Self-talk; (2) Cooling and Calming Self-talk; (3) Self-talk Coaching; (4) Corrective Self-talk. 

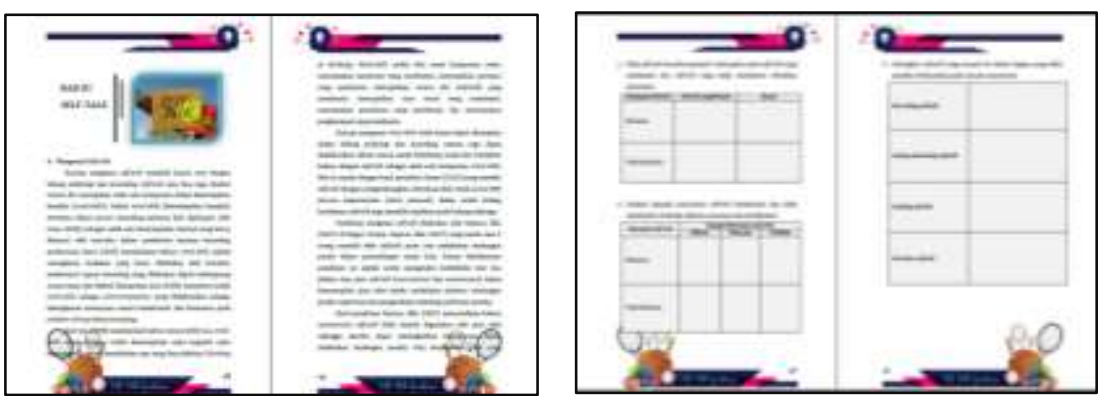

Fig. 3 Content of chapter 3 and instructional quetions that must be answered and conducted by athletes

Chapter 4. This chapter contains a strategy of implementing self-talk in which this chapter presents illustrations of cases that are familiar with sharing the type of self-talk. For example when athletes do self-talk but direct towards negative self-talk, there are directions and ways for athletes to be able to apply self-talk correctly so that when athletes speak that make them lose concentration, lack of confidence, do not feel the spirit can be changed into positive self-talk that can increase arousal, reduce anxiety, increase selfconfidence and concentration which will directly affect the athlete's mindset and affect the athlete's performance. And in each session, a type of case is given for athletes who will apply self-talk to practice on their own according to the stages of each type of self-talk.

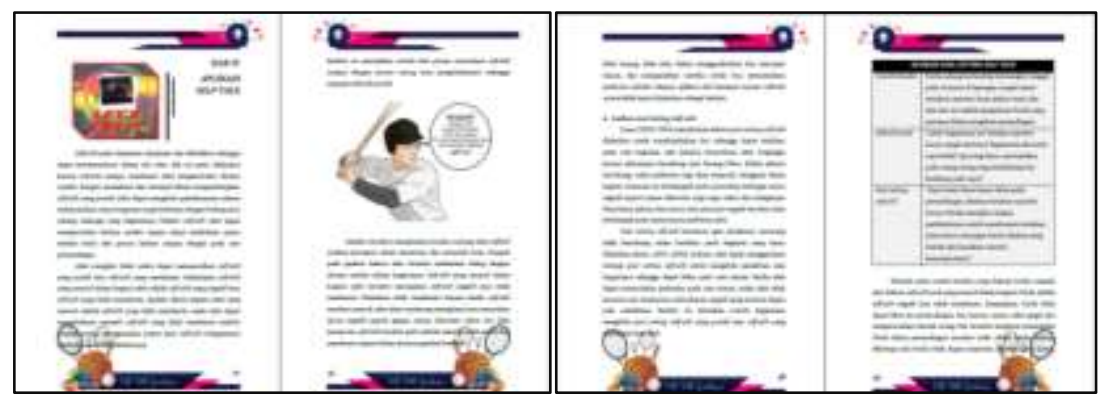

Fig. 4. Content of chapter 4 and ilustrate in each type of self-talk 
Based on the results of expert judment by the expert, the following data were obtained

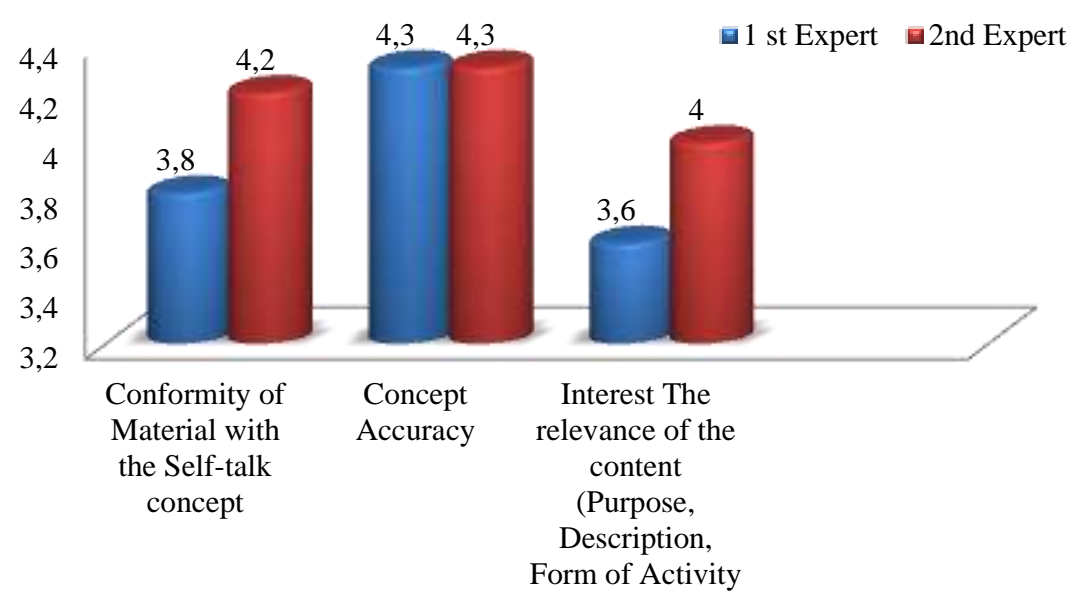

Fig. 5. Diagram mean result expert judgment of self-talk guidance

Based on the table above, it is known that the result of the first expert was obtained a mean of 3.9 and is categorized very good while the second expert with a mean of 4.2 with an excellent category. Based on the results of the first expert discussion said that the book can help the athletes based on research, but there need to be revisions such as add research results to strengthen why self-talk is effective to use, give illustrations of world elite athletes who use self-talk. While the second expert reveals the whole book can help athletes to improve their psychological skills. What needs to be added is the concept of sports psychology is not only about psychological techniques, but also added psychological aspects in sports. After discussing the aspects of sports psychology it is more obvious to enter into a psychological intervention strategy where this strategy is intended to improve the psychological aspects of athletes ' psychological skills.

The results of expert judgment will be calculated product feasibility test. Product feasibility test results obtained from the first expert is $78 \%$ and form the second expert is $83,64 \%$. According to data on the results of the product feasibility test from the two experts stated that the product is feasible to use. That means the product is ready to be continued in the next phase, which is the implementation phase and ready to be used as a trial product.

\subsection{Discussions}

Development using the ADDIE model is mostly used as a basis for making instructional assignments for individual learning in a learning environment. The appli- 
cation of the ADDIE concept is designed for a supportive system to facilitate the complexity of intentional learning by addressing variations. In this study using ADDIE because R. Branch explains that ADDIE can be used depending on the context in which ADDIE is applied. The Center for Instructional Design on individual learning has a direct and long-term learning phase. ADDIE considers the process of making products most effective because ADDIE is a process that functions as a guide to complicated work discussions that are appropriate for developing educational products and other learning resources [16].

The same thing as this self-talk implementation manual is because the book is focused on athletes to learn various intervention strategies as a training process to improve psychological skills. The development of the Self-talk guidance book is designed so that athletes can apply self-talk techniques with various types of self-talk following the situation being faced both during practice and during training. That is the reason researchers use the ADDIE concept as a development model for this book.

Based on the results of studies that have been submitted by researchers that the Self-talk Guidance book is ready to be tested, then why is the Self-talk guide book? Research related to self-talk in sports has been tested and has its limitations. The effectiveness of the use of self-talk has shown significant results such as research by Antonis Hatzigeogiardis et al (2017) who examined the effect of self-talk on attention from the results of this study that self-talk is an intervention strategy that can improve performance in sports. Self-talk has a beneficial effect on attention. Recommendations from this study are important for developing theories and comprehensive information to provide self-talk practice [18]. A similar study by $\mathrm{Yu}$-kai Chang et al (2016) which compared motivational self-talk and instructional self-talk from the research results concluded that both experimental groups had better results on the performance of softball athletes than the control group and the recommendations of this study motivational self-talk have better results than instructional self-talk [19].

Findings related to self-talk that support in facilitating learning and improving the performance of task implementation need to have a strategy and a plan that must be strongly encouraged. Regardless of any purpose, if the research does not yet support all the functions that can be carried out by self-talk, but when self-talk is designed well and carefully according to individual needs, this self-talk will have a significant affect such as increasing attention, regulating cognitive reactions and emotions, increase self-confidence, trigger automatic performance, and increase motivation [20].

Based on previous studies results, an outline the implementation of self-talk will greatly benefit if the application of self-talk is well designed and carefully adjusted to the needs. As well as providing appropriate information on implementing self-talk intervention strategies. The development of the Guidance Self-talk was indeed designed and made so that athletes could obviously know the self-talk intervention strategy properly and correctly. In addition, athletes can learn to use self-talk either accompanied by a coach or not and use self-talk in various situations both during training and competition. 


\section{Conclusions}

This study aims to design and develop a book on the application of psychological self-talk intervention strategies, namely self-talk guidance intended for athletes. This study uses the concept of developing ADDIE models that are focused on athlete learning can be practice self-talk intervention techniques/strategies in a variety of situations. The results of the study indicate that the development of the book "Self-talk Guidance" is appropriate to be used and continued at the implementation stage of product trials. Self-talk is a psychological intervention strategy that is widely used and recommended by researchers to improve psychology skills for athletes. The design of giving self-talk intervention strategies needs to be carefully considered according to the needs of athletes so that self-talk can provide significant benefits.

\section{Acknowledgments}

This study would not have been possible without the help that I received from all of my friends, colleagues. To begin with, we would like to acknowledge the honorable both of the experts who helped this study running well and give the suggestions and best recomendation for best quality the Sself-talk Guidance. Expert are in sport Psychology is Mr. Donny Wira Yudha P.hD and from Guidance and Counseling is Mr. Mulawarman P.hD. Next acknowledge for my partners who have contributed in developing the contents and structure of Self-talk Guidance book, Eni Rindi Antika.. And all research members who have contributed to run this research. This study was granted by Faculty of Sports Science, Universitas Negeri Semarang (DIPA FIK UNNES Tahun Anggaran 2020).

\section{References}

[1] Birrer D, Morgan G. Psychological skills training as a way to enhance an athlete's performance in high-intensity sports. Scand J Med Sci Sport. 2010;20(SUPPL. 2):78-87.

[2] Sindik J, Novokmet N, Havas-Augustin D. The application of psychological skills inventory for sports at Croatian coaches and recreational table tennis players. Sport Sci 6. 2013;1(2014):54-60.

[3] MacNamara Á, Collins D. Profiling, exploiting, and countering psychological characteristics in talent identification and development. Sport Psychol. 2015;29(1):73-81.

[4] MT Elferink-Gemser, C Visscher. Who are the superstars of tomorrow? Talent development in Dutch Soccer. In: In Talent identification and development in sport. London: Routledge; 2013. p. 115-25.

[5] Weinberg RS, Daniel G. Foundation of Sport and Exercise Psychology. Sixth Ed. 2015.

[6] Thelwell R, Weston N, Greenlees I. Examining the use of psychological skills throughout soccer performance. J Sport Behav. 2010;33(1):109-127.

[7] Behnke M, Tomczak M, Kaczmarek LD, Komar M, Gracz J. The Sport Mental Training Questionnaire: Development and Validation. Curr Psychol. 2019;38(2).

[8] Zourbanos N, Hatzigeorgiadis A, Chroni S, Theodorakis Y, Papaioannou A. Automatic self-talk questionnaire for sports (ASTQS): Development and preliminary validation of a measure identifying the structure of athletes' self-talk. Sport Psychol. 2009;23(2):233-51.

[9] Gentili R, Han CE, Schweighofer N, Papaxanthis C. Motor learning without doing: Trial- 
by-trial improvement in motor performance during mental training. J Neurophysiol. 2010;104(2):774-83.

[10] Hatzigeorgiadis A, Galanis E, Zourbanos N, Theodorakis Y. Self-talk and Competitive Sport Performance. J Appl Sport Psychol. 2014;26(1):82-95.

[11] Velentzas K, Heinen T, Schack T. Routine integration strategies and their effects on volleyball serve performance and players' movement mental representation. J Appl Sport Psychol. 2011;23(2):209-22.

[12] Hardy J, Gammage K, Hall C. A descriptive study of athlete self-talk. Sport Psychol. 2001;15(3):306-18.

[13] Hatzigeorgiadis A, Zourbanos N, Goltsios C, Theodorakis Y. Investigating the functions of self-talk: The effects of motivational self-talk on self-efficacy and performance in young tennis players. Sport Psychol. 2008;22(4):458-71.

[14] Hatzigeorgiadis A, Zourbanos N, Galanis E, Theodorakis Y. Self-talk and sports performance: A meta-analysis. Perspect Psychol Sci. 2011;6(4):348-56.

[15] Latinjak A, de las Heras B, Sacot A, Fernandez D, Robinson D, Lane A. Effects of Reflection to Improve Goal-Directed Self-Talk on Endurance Performance. Sports. 2018;6(2):55.

[16] Branch RM. Instructional Design. Instructional Design: The ADDIE Approach. New York Dordrecht Heidelberg London: springer; 1978. 1-190 p.

[17] Shelton K, Saltsman G. Applying the ADDIE model to online instruction. Adapt Inf Commun Technol Eff Educ. 2007;(October 2004):41-58.

[18] Hatzigeorgiadis A, Galanis E. Self-talk effectiveness and attention. Curr Opin Psychol [Internet]. 2017;16(d):138-42.

[19] Chang YK, Ho LA, Lu FJH, Ou CC, Song TF, Gill DL. Self-talk and softball performance: The role of self-talk nature, motor task characteristics, and self-efficacy in novice softball players. Psychol Sport Exerc. 2014;15(1):139-45.

[20] Theodorakis Y, Hatzigeorgiadis A, Zourbanos N. Cognitions: Self-Talk and Performance. 2012. $1-42 \mathrm{p}$. 